\title{
"El Murciélago" en la Literatura Peruana (1).
}

Agudo, pequeño, noctívago, de una peligrosa voracidad para con la sangre de las gentes, el Murciélago desenvuelve su leyenda bajo los techos artesonados de las viejas casonas coloniales, que sobreviven en plena república con rango y señorío. Mamífero volador, luego de herir con su pluma hasta estallar en sangre, se refugia en las altas vigas, desde donde observa el paso del Perú, de una senectud colonial sin horizontes, hacia una promisora y desordenada vida republicana. Consultando sesudos tratados, sabíamos que los murciélagos se repartían en diecisiete familias, $y$ " que "La mayor parte son insectívoros, pero algunos chupan sangre (los vampiros) y otros comen frutas; y compensan su poca vista con un tacto exquisito". Así queda explicada la línea vital de nuestro gran satírico. A veces lo observamos en la beatifica actitud de saborear las más inocentes frutas y otras, en cambio, con el agresivo ademán del que indaga por las hondas arterias de la nacionalidad: pero siempre "con tacto

Este ensayo se completa con mi estudio sobre la "Contribución de Ma. nuel A. F'uentes al Derecho Peruano", que se publica en la Revista de Derecho Internacional, y con mis apuntes sobre "Otros aspectos de la Obra de "El Murciélago". 


\section{$-310-$}

exquisito", suprema condición de su destino de luchador y artista.

\section{Primavera republicanna.}

Simbólicamente Manuel A. Fuentes nace en momentos en que la independencia americana se consolidaba promisoramente. Abríase para el Perú una nueva época, en la que a nuestro gran satírico le correspondería actuar intensamente. Primavera republicana, agitada con los impulsos y vacilaciones de una juventud que no conjuga el verbo esperar. Novedad de formas y horizontes para gastarse en conocerlos sin economia, ni cautela. En este tráfago que como un torrente quedó entremezclado con las revoluciones de los primeros años de nuestra vida independiente, la breve figura del 'Murciélago pugnó por hacer oir su palabra. Pudo ser absorbido, por instantes, en este agitado tumulto; pero con la olímpica soberbia de los pequeños, se erguía siempre, presto a cumplir su rol. Sin rectificación, la crítica, lo ha equiparado a nuestros más grandes satíricos; y fué, en verdad, un periodista de raza, cuyo constante contacto con la realidad europea, concedia amplitud y nobleza a su ademán.

No provenía Manuel A. Fuentes de altas ejecutorias hispanas, pero sí de una límpida línea genealógica que respaldaba hidalgamente la dignidad de su espíritu, y la noción de la jerarquía que fué preocupación angular de su vida. Nacido el 2 de Mayo de 1820 , era hijo del Dr. Francisco Fuentes, catedrático del Colegio de la Independencia, y cirujano patriota, compañero de Bolívar en sus campañas del Perú. Su madre Andrea Delgado descendía de un Oidor de nuestras Audiencias virreynales. Hogar lejos de todo ornato o brillantez excesiva, sino antes bien austero y de callada 
gravedad. Allí Manuel A. Fuentes tuvo la primera intuición de la doctrina de lucha y de trabajo que le corresponderia afrontar.

Una educación doméstica y religiosa, que recuerda más tarde con cariñosa ironía, dió una vaga tonalidad a sus años infantiles, en los que las figuras de doña Peta Carrasco y doña Dolores Portocarrero, dibujan la teoría de sus primeras letras. A los siete años cumplidos concurre al Aula de Latinidad de Justo Andrés del Carpio, arequipeño profesor de latín e importante conductor de niños por los deslumbrantes senderos de las letras. Pronto, abandonando sus salones, corre a incorporarse como alumno del Museo Latino del eminente José Pérez de Vargas, valiente y afortunado poeta, compositor de rimas laudatorias a personajes ilustres.

Pero Manuel A. Fuentes, tenía una vocación múltiple. Con igual comodidad abordaba las truculentas dificultades de la preceptiva poética, como los exactos y precisos problemas matemáticos; e igual devoción y curiosidad inspiraban a su espíritu las ciencias físicas y biológicas, que el interés definitivo y picante de los tortuosos caminos de la filosofía - las sorpresivas revelaciones del Derecho. Así lo vemos de bachiller en Filosofia y Cánones a la edad de diecisiete años, y de estudiante de Matemáticas, al mismo tiempo que recibía lecciones de jurisprudencia de José Manuel Tirado. Sin embargo, el ejemplo de su padre era demasiado seductor, y en sus ilusiones juveniles, su propósito más firme era seguir la carrera de la Medicina.

Un acontecimiento lamentable e inesperado conspira contra su porvenir. El año $\mathrm{I} 837$ fallece el Dr. Francisco Fuentes en Jauja, y Manuel Atanasio, percibe cómo su desaparición, puede ahogar sus más caros proyectos. No obstante, el padre, había sido de los hombres que saben dejar amigos aún después de la muerte, y el General Santa Cruz 
y el Dr. Cayetano Heredia, favorecen los deseús del joven aspirante.

Contra lo que se hubiera podido imaginar, el destino tenía trazados otros planes respecto a su existencia. Vaivenes de la vida republicana hacen que el Colegio de la Independencia sea clausurado con fines de reforma, y Fuentes, casi sin saber cómo, un buen día debuta en el periodismo en forma promisora, publicando el "Busca-Pique”, el año I839. Epoca de agitado pasar, trabaja con el general Trinidad Morán: luego se siente perseguido y se esconde para reaparecer ante Gamarra que lo trata, con la consideración al hijo de un antiguo amigo; más tarde se enrola en el batallón cívico "Comercio" al mando de don Domingo Elías, y en todas esias aventuras tiempla. el carảcter y adquiere esa excéptica actitud ante la realidad que ha de impregnar sus escritos.

Pero su idea fundamental persiste en la Medicina, y continúa sus estudios alternándolos con las actividades juríd:cas. Una nueva y afortunada interrupción trunca en estos momentos su carrevá. El Colegio de la Independencia desea dar una orientación modentai a sus estudios, y la adquisición de los laboratorios indispensables debe realizarse bajo la mirada de una persona inteligente. Entonces, el Dr. Cayetano Heredia, se acuerda de Fuentes y lo hace llamar. Viaje inesperado y soñado, agita el ánimo del muchacho, tanto como la elocuente prueba de confianza que acaba de recibir. Corre el año I845 y Fuentes marcha a Francia; en sus bolsillos, entre muchas cartas, lleva una del Dr. Heredia, que con cariño paternal lo recomienda a París: "Sin embargo que tengo demasiada confianza en este joven,-escribe Heredia-y que por lo tanto lo he elegido entre otros muchos; su edad y el país lleno de atractivos donde va, me ponen en el 
deber de stiplicar a Ud. que le dé aquellos consejos que considere más oportunos para evitar cualquier extravío..."

La misión, como era de suponerse, fué cumplida con eficiencia; y, simultáneamente, Fuentes recibía una impresión perdurable en su vida. Había comprobado la necesidad de renovar al ambiente del Perú, con las enseñanzas adquiridas en la riqueza y gallardía de las grandes culturas europeas. Así, con nuevos ideales y proyectos de trabajo, se embarca de regreso al Callao a fines del mes de Enero de I846.

Es un momento crucial en la vida del escritor. Escoge la' carrera de las leyes que tan amplias perspectivas habia mostrado ante él. Y, un buen día, tiene la intuición de que ha conocido a la persona destinada a ocupar el lugar definitivo en su existencia. Año de 1846 , en que sus afanes por recibirse de abogado se alternan con la presencia e intimidad de la que ha de ser su esposa. Luego de contraer matrimonio con María Font, una bella muchacha de ascendencia española, a las pocas semanas viaja a Huánuco, a hacerse cargo de la Judicatura de ese lugar.

No fué muy grata, ni afortunada la primera experiencia de Manuel A. Fuentes en la magistratura. La vida de provincias se encargo de depararle sorpresas, de cosas que todavía ignoraba. Toda una batería de calumnias, enemistades y acusaciones, oculta bajo los apropiados camouflages de la hipocresía cotidiana, se encargó de entorpecer sus inocentes propósitos de trabajo. Pueblo chico, de acuerdo con el refrán, fué para Fuentes grandísimo infierno, donde su honor recibió ataques de muy complicado refinamiento. Queriendo no vir, laboraba románticamente porque la cárcel y el hospital de la ciudad, adquirieran la dignidad que a él amenazaban quitarle. Pronto la pugna se volvió insostenible, y tuvo que renunciar a su cargo, dolido de la ingratitud del pueblo donde habían nacido sus dos primeros hijos. 
Este reintegrarse a Lima el año I850 tiene evidente in:portancia para su derrotero futuro. Sin descuidar su profesión de abogado, no deja de interesarse vivamente por la política. Sus comienzos no son muy optimistas, pero satisfacen su espíritu de lucha. Partidario de Vivanco, el triunfo de Echenique le importa una pausa. Luego viene Castilla; a los ocho días de haber subido al poder, el primer artículo de oposición es escrito por Fuentes. "El Murciélago", con una previda en 1844 , cobra carta de ciudadanía, y se convierte en diario, a partir de Enero de 1855 . Su franqueza en el ataque, provoca represiones que lo obligan, al fín murciêlago, a refugiarse en una de esas altas vigas del techo del Perú.

La enemistad de Fuentes con Castilla fué violenta pero pasajera. De su violencia tenemos testimonio en su panfletaria biografía del general, escrita en Chile durante su destierro; de la dulce reconcifiación que siguió a su odio, queda testimonio en un pasaje de su autobiografía, escrita años después, donde expone sus razones para trocar en amor la violencia de antaño. La verdad de todo es que Castilla, gran conocedor de lôs hombres, sabía atraerlos con una sabia política en cuya alguimia encontraban mezcla en partes iguales, una ladina viveza criolla llena de desenfado, y una natural generosidad de ánimo que derribaba muchas irreductibles torres.

Pero no era exclusivamente la política, la que absorbía su acción. A partir de 1857 , época en que prepara su famosa "Estadística General de Lima", la actividad publicitaria $\mathrm{de}^{\prime} F$ untes deriva a los más diversos campos. Su capacidad de trabajo es verdaderamente desconcertante. Edita la colección de "Causas Célebres" y las "Memorias de los Virreyes" y reedita el "Mercurio Peruano", bajo la complaciente protección de Castilla. Simultáneamente, como melancólicas 
reminiscencias de sus primeros estudios, da a luz una Higiene Privada y una Higiene de la Infancia. (Hay que recordar que años más tarde llega hasta preparar una Historia Sagrada, con permiso eclesiástico y todo lo demás). En el campo periodístico, a la aparición de "El Mercurio" siguicron sus colaboraciones en "El Heraldo" y su intervención en "El Monitor de la Moda", "El Semanario" (para niños) y "El Semanario Satírico". El año de I862 estableció un magnífico taller tipogrático donde editó "La Epoca" siendo jefe de redacción José Arnaldo Márquez, y a partir de Octubre de I862 "El Mercurio", desde donde el Murciélago polemizó pintorescamente con José María Samper.

Los años siguientes son de intenso trabajo. Su labor juridica ocupa lo mejor de su existencia hasta su muerte. También son frecuentes los viajes a Europa, donde fija la residencia de la familia, para que sus hijos puedan adquirir una educación europea. Anima "La Gaceta Judicial", edita diversas obras de Derecho y compone su "Guía de Lima". Durante su permanencia en Francia publica la segunda edición de su "Estadística@General de Limâ" los tres tomos de "Aletazos del Mưrciélago", cynsti] nueva obra "Lima" hecha a base de las anteriores, y con magnífica generosidad poliglota.

De regreso al Perú en r867 interviene en los campos más diversos. ¿Cabe extrañarse, acaso, de que sea Futentes quien proyectó y llevó a cabo el Palacio y los parques, donde se inauguró la Exposición Internacional de Lima en el mes de Julio de 1872 ?. Durante tres años había trabajado infatigablemente en esta obra y con fruición infantil intervino como expositor desde los ángulos más inconcebibles. Todavía la familia conserva los diplomas obtenidos, tanto por haber exhibido una muy completa colección de textos de colegio 
cuanto por la gordura de un magnífico cerdo de su propiedad.

Epoca en que, a partir de I868, se hace cargo de la Imprenta Oficial, según contrato pactado ante Claudio Stuárez, en que se comprometía a "refaccionar la casa situada en la calle de la Rifa, de propiedad del Estado y de hacer en ella todos los trabajos necesarios para reunir y organizar la Imprenta del Estado", labor que lleva adelante con seguridad y conocimiento. Los años siguientes, también los consagra a otra gran obra: la venida del eminente profesor francés Pradier Foderé, con cuya intervención se crea la Facultad de Ciencias Políticas y Administrativas en la Universidad Mayor de San Marcos; Doetor Honoris Causa de esta Facultad, Manuel A. Fuentes ejercía, en tanto, la cátedra de Medicina Legal en la Facultad de Derecho, y luchaba por que la nueva etapa de "La Gaceta Judicial", fuera de singtlar brillantez.

Nuestro escritor pasa en plena y agitađa acción esa terrible línea de los cincuenta años, que pone una nota de reflexión en el ánimo de los hombres. Lasúltima etapa de su ivida, la pone al servicio de tareas de honda trascendencia. Renuncia al "cargo de Secretario del Congreso Internacional de Jurisconsultos en 1876 , pero en cambio acepta la Dirección de Estadística en 1877 , sabiendo lo dura y agotadora de la labor que se había impuesto. El da una nueva fisonomía y una moderna estructura a este departamento y numerosas publicaciones atestiguan lo definitiva y saludable que fuc su presencia en esta repartición, para la futura orientación de la Estadística en el Perú.

Octpa el cargo de Fiscal de la Corte Suprema y el Decanato del Ilustre Colegio de Abogados en los años r 869 a 1872. Pero su fibra patriótica no puede congeniar con la 


\section{$-3^{17}-$}

presencia del enemigo en su propio país, y tiene que abandonar Lima y radicarse en Guayaquil, donde reapareció "El Murciélago", en los años de I884 y I885. De regreso al Perú fué elegido Fiscal de la Corte Suprema. Sin embargo, a los dos años de desempeñar sus funciones, sintiéndose agotado se retiró a descansar. Poco después, el 2 de Enero de I889. ṫalleció a la edad de 69 años.

\section{GEINIO Y FIGURA.}

Con absoluta y justificada razón vosotros podríais preguntarme cuál era la figura de quien tan múltiples y peregrinas actividades se permitió tener en el campo de nuestra agitada vida republicana del pasado siglo. Yo podría, con audacia o malevolencia, for jar un retrato convencional, deslumbrante en virtudes y negado en defectos, como un paladín de nuestras libertades o un delicado pintor de nuestras costumbres. Todo ello estaría muy bien, pero no sería cierto; y felizmente para mí y para vosotros, el propio Murciélago tuvo la previsión de dejar datos para su pasaporte a la posteridad, y los of reñdó contlacgenerosidad ques caracterizaba todos los actos de $\mathrm{Su}_{\mathrm{r}}$ vida.

Debo advertiros, sin embargo, que esgrimió su ironia contra sí mismo, no sabemos si por esa amargura que nuncá abandonó su espíritu; y su semblanza no es retrato sino caricatura, hecho por quien tanta práctica tenía en exagerar los razgos de los demás.

"Avara de huesos fué conmigo la Providencia-dice e! Murciélago_dióme los necesarios pero pequeños..... mido vara y menos de cuarta, y pesaré, a lo más, noventa libras, inclusas las ropa y las patillas; este peso merma consideraque me he esforzado, no he podido conseguir hacerme $u n$ 
hombre de peso y dudo mucho llegar a obtener semejante dicha......'.

Esto es lo que podría llamarse una visión panorámica de su persona. Pero inmediatamente entra en detalle y escribe: "Mis cabellos son negros, lacios y gruesos y desmienten muy irrespetuosamente la aserción de mi misma madre de que fueron rubios, crespos y delgados.... Los uso cortos $y$ sólo llevo un pequeño moño o cola de gallo sobre la frente..... Mi frente es ancha y bien desarrollada. Hanme dicho que esa es señal de inteligencia, pero yo dudo much de tenerla, porque hasta ahora no he puesto mano en cosa que no me haya salido al revés de lo que había imagina-
do.....".

Al tratar de sus ojos, emprende la reivindicación de los ojos pardos, tan genuinamente peruanos, y dice: "Mis ojos son indefinibles; no tienen ni el fuego de los negros, ni la ternura de los azules, ni la melancolía de los verdes, ni la viveza de los chicos, ni la arrogancia de los grandes, ni lo aterrador de los saltones, que llamamos en mi país de huevos duros, porque no son de ninguna de estas clases. Son medianos y pardos, $y$. desconozco los atributos de tal especie. No ha faltado quien me diga que son vivos, y no me causa dificultad creerlo así....".

En lo que respecta a su nariz, no resiste al deseo de. compararla con algunas famosas narices de su tiempo: "Igual dificultad encuentro para clasificar mi nariz: ni es borbónica, ni es paz-soldánica. Si me llamo narigón, miento; si chato, falto a la verdad" y concluye aceptando, lo que llamaríamos, una nariz ecléctica. En su boca, en cambio, reconoce no existir tanta mesura: "Tengo el labio inferior muy grueso y el superior no delgado, y presumo que la providencia quiso darme ese órgano a propósito para tocar cornabacete u otro instrumento de esa clase". 
Después de esta seria revisión sus conclusiones son un poco melancólicas: "El todo de mi cara no tiene la forma ovalada del romanticismo, ni la redonda del magisterio, y está adornada de un par de patillas redondeadas a la española, poco crespas y poco pobladas pero que me dan tal cual aspecto varonil". Es decir, que se salva por las patillas.

Hasta aquí, el propio Murciélago logra los trazos de su realidad física y nosotros nos lo podemos imaginar como un hombrecillo breve y nervioso, provisto de una mirada maliciosa, donde de tiempo en tiempo, descubrimos una chispa malévola, y con una tenacidad y una voluntad de trabajo, capaz de vencer las mayores dificultades. Pero nos falta algo esencial. Su retrato moral. Pensamos, que la simple lectura de dos cartas, que inserta en su autobiografía, nos permitirá revelar, con elocuencia, su incontrastable posición de crio1lo atrabiliario.

Cuando Manuel A. Fuentes editaba "El Mercurio", uno de sus cronistas se propuso inaugurar una sección titulada Semblanzas Oratorias, donde se iba a presentar en forma caricaterezca a algunas personas de Lima. Uno de los presuntos agraviados era el senor. Fernando B., quien al enterarse del posible ataque, manifesto que si aparecía tal publicación daría de palos al Murciélago. Súpulo Fuentes y reaccionó curiosa y violentamente. Transcribo, sin otro comentario, los textos de las cartas cambiadas entre Fernando $\mathrm{B}$. y Manuel A. Fuentes:

"Lima, Setiembre 5 de 1863.

Señor Fernando B.

Muy señor mío:

Sírvase U. decirme a continuación si es cierto que algu- 
na vez me haya $U$. ofrecido personalmente, o por otro medio, dar de palos si yo escribo contra. U.

Soy de U. atento y S. S.

\section{Manuel A. Fuentes'.}

"Señor Dr. Don Manuel A. Fuentes.

Muy señor mío:

No recuerdo haber, jamás, ofrecido palos a U. ni directa, ni indirectamente, pues en la armonía que guardamos no cabe semejante desatino.

Soy de U. atento y S. S.

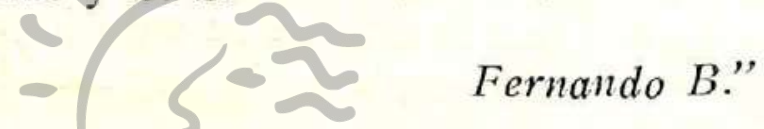

Curioso y contradictorio, el espíritu de Manuel A. Fuentes, era, al mismo tiempo, apasionadamente panfletario, y abandonadamente escéptico. Unía el calor de sus violencias a la frialdad tajante deesü itontas En el fondo una nota de amargura g de melancolíatiñe de un tono oscuro sus escritos. Su agilidad en la actitud y su agudeza en la broma lo erigen, por esencia, en alto criollista de nuestra literatura.

\section{LAS HAZAÑAS DEI MURCIRLAGO.}

\section{"Definir el escribir es dificil definir...."}

No se podría comprender la trascendencia del periodismo satírico en nuestro siglo pasado, sin dirigir una mirada de soslayo a la realidad política del Perú. Ensayo de vida republicana por un pueblo individualista en exceso; 
etapas de euforia económica y de aplastante depresión; caudillaje lleno de demagogia pero también de sinceridad; voluptuosidad y sentido de aventura en el poder: Todo ello son fuerzas y notas que se entremezclan y condicionan el paisaje social. Pero en este tumultuoso navegar de la nave del Estado, el periodismo cumple con toda convicción su papel de intérprete, no de la opinión pública, sino de una serie de públicas opiniones, encontradas y apasionantes El ataque es violento y con frecuencia cae en la diatriba personal; pero con igual facilidad se eleva hacia niveles de la más sana fé constructiva. Así prospera un nutrido y pintoresco periodismo, cuyas cifras 'son, en muchos casos, de muy corta vida; y en'otros, fluctuantes con el termómetro de la temperatura política. Pero siempre revelan novedad y vigor en el ataque; talento $\mathrm{y}^{i}$ sagacidad en la palabra; agilidad y audacia en el pensamiento: Este es nuestro periodismo satírico, marco y perennidad de nuestra vida republicana.

"El Murciélago" supo cumplir con atrevida lealtad su destino mortal. Cuandoerte855 seepresenta en todo su vigor, ya tenía dos precedentes en la conciencia periodística de $\mathrm{Ma}$ nuel A. Fuentes: uno era el Busca-pique de 1838 y otro su propia anatomía del murciélago de 1844 . No era tampoco animal raro en nuestro mundo. El mismo Fuentes comprueba en su Estadística General de Lima, cómo en los años que transcurren entre I82 I y I855, se habían editado no menos de 128 periódicos, de los que sólo i2 había sido oficiales, y en cambio, 83 se habían ocupado "de asuntos políticos exclusivamente" sin contar otros ro dedicados a "política y lite-ratura". Se comprende fácilmente que esto de literatura era para despistar.

En este incomparable y alentador panorama periodistico, la figura de "El Murciélago" no podía aparecer como de- 
masiado excéntrica. Nombres muy expresivos habian prohijado agudas hojas volanderas. Habíamos tenido "El Cañón" en I833; "El Coco de Santa Cruz" en I835 "El Miércoles de Ceniza" en I843 y "El Zurriago" en I848; sin contar con ctros bullangueros pobladores de nuestra fauna editorial como "El Loro" de I822; "El Papagayo" y "La Cotorra" de I829 o "El Tío del Montonero" surgido el año de I834. Hubo periódicos que, en su extremada sinceridad, traslucian sus intimidades, y tenemos que confesar que "El Vılantuso" fué de 18,32 , mientras que "E1 Desengaño" correspondió al año I 824 , en los albores de nuestra vida repubilicana.

Una definitiva intensión politica animó la aparición de "E1 Murciélago". Mamífero volador, destructor de animalillơs y, en ciertos casos, ávido de sangre, no vaciló en considerar constitucional o inconstitucionalmente insectos a sus enemigos políticos. Hay oportunidades en que el ataque es acre y de tono personal, pero con igual frecuencia despliega su vuelo hacia el deseo de una necesaria regeneración del Perú.

Apasionado en sus opiniones, por instantes, el aguijón de su crítica calámul hondo y su palabra es dura para marginar un campo o indicar una ruta. Es el áspero sabor de las páginas de su "Catecismo para el pueblo", al analizar los conceptos de una libertad humillada, de una patria que consideraba espoliada por la tiranía, o de una soberanía que los hechos contribuian a desnaturalizar. Por eso cuando llega el 'momento de definir las garantías, escribe:

¿"Qué cosas son las Garantías?

- Son cosas que se llaman garantías

¿Cuántas clases hay de garantias?

-Dos, que son las calientes y las frías.

¿Cuáles son las calientes? 
- Las que se han hecho para mortificar a las gentes.

¿Y las frías? días".

-Las que se han hecho para mortificarlos todos los

Tiene muy mal concepto del talento de los ministros, porque descubrió que uno, sin darse cuenta, había escrito contra sí mismo, y entonces, El Murciélago, afirma enfáticamente: "Háganme Ministro y no hago la oposición". Un buen día se pone meditabundo y escribe una "Relación de los personajes que han querido hacernos felices y no han podido conseguirlo" donde figuran desde el General San Martín hasta Echenique, con un total de 35 presidentes para 34 años de vida republicana. Su análisis de la Constitución y de la Ley de Elecciones del año 55, es demasiado conocido para que yo trate de insistir sobre la materia.

Prefiero hacer resaltar otro aspecto de "El Murciélago" cuando se aparta del campo exclusivamente político, para pintar magníficos cuadros de nuestra realidad, como to podia haber hechoB Felipe Pardo y Aliagarasquien le unia su sentido europeo de las proporciones-Manuel Ascencio Segura-que guardaba con él identidades de esencia popular-, o en último caso, el propio e imponderable Juan de Aroma, visión universal y local equilibrada y precisa.

Fuentes tiene castiza gallardía cuando, escribe sobre la trascendencia de la pechuga en el Perú, y entra en el análisis del contenido de la pechugonada; cuando no tolera los atentados dramáticos de los malos poetas patrióticos; o cuando, finalmente, se indigna del cinismo de cierto empresario que anunció en la plaza de Acho la lucha entre un toro y un oso, y cuando el público había cumplido con llenar los tendidos y los bolsillos del audaz, el oso no dió muestras de 

espiritu combativo, sino antes bién trocose en "cobarde y co-
sredor".

No era muy optimista respecto a la originalidad de los limeños para celebrar las Fjestas Patrias, y avecinándose las del año 6o, escribe:

"Fiestas del Aniversario.-Su misa de gracias de costumbre, con su sermón de costumbre; su palo encebado de costumbre; sus trapitos en el Cabildo de costumbre; sus tubos de plomo en palacio con sus agujeritos para que el gas haga la iluminación de costumbre; sus Seamos Libres de costumbre; sus fuegos artificiales peores que de costumbre......".

Pero, en cambio, en otras oportunidades, exhibe un pinpante optimisno, como cuando exalta las virtudes de los baños de Huacachina, relatando maravillosos acontecimientos como aquel de:

"Doña Juana Plazuelos, viuda honesta de 74 años de edad tuvo la desgracia de perder el uso de la palabra a consecuencia de la muerte de su espōso ocurrida en la Batalla de Ayacucho: por consejo de una comadre suya, se dió un baño con agua de Huacachina y al cuarto de hora principió a hablar con tal vigor y fuerza que no han bastado siete canastas para recoger las palabras que arrojó en media hora". $Y$ sostiene que no solamente se consiguen beneficios intelectuales sino también materiales:

"A don José Travitazo le vaciaron los ladrones un ojo $y$ ha carecido de este instrumento por más de quince años; con tener el cuidado de lavarse la vivienda vacía todas las noches con Huacachina, ha conseguido tener un hermosoojo nuevo, sin más inconveniente que el haberle salido verde, seguramente por ser esa el color del agua..."

Sin embargo, a veces, El Murciélago pierde la sereni- 
dad por virtud de una cólera politica, o de alguna polémica tan enconada como la que sostuvo con José Ma. Samper. Y aunque en estas ocasiones su estilo decae visiblemente, pronto la pasión cede paso a un cinismo lleno de simpatía que da levedad y colorido a sus escritos. .

Durante el largo paréntesis de El Murciélago, la caudalosa e inagotable vena satírica de Fuentes tuvo muchas manifestaciones. Una, muy singular, está representada por "La Broma", periódico satírico que tuvo la virtud de unir los nombres de Palma y Fuentes. "La Broma" se publicó entre el 15 de Octubre de 1877 y el 27 de Abril de 1878 . En esta fecha los siete colaboradores resolvieron enterrar el periódico, y fué Palma quien escribió el epitafio.

Como un gallardo producto de esta nueva arentura, está el "Juicio de Trigamia", folleto en verso entresacado de las columnas de "La Brona". Pleito ruidoso lo califican sus autores: Miguel A. de Ta Lama, Ascisclo Villarán, Manuel A. Fuentes, Ricardo Palma, Eloy P. Buxo, Julio Jaimes y Benito Neto. La predilección por la sátira jurídica era antigura en Fuentes. Basta recordar su "Villarancidio... o asesinato de un Poema extraído del Murciélago de 1858 o st “Bofetón circunstanciado..." publicado en I859.

En el Juicio de Trigamia se trata nada menos que del Teniente Amador Toro Espada, apuesto y débil de corazón, que luego de contraer matrimonio con Justa Cornelia Vaca Ganosa, por razones de servicio es trasladado a Arequipa y Moquegua, donde con igual lealtad contrae nupcias con Guillermina Azul y Rosa y con Mariquita Molina. El tema, permite a los redactores de "La Broma" verdaderas filigranas de su ingenio poético.

Para concluír la revisión de este aspecto de Fuentes, quiero recordar su "Aforismo Peruano", que en la brevedad 
de su única estrofa, lo acredita como genuino representante de nuestra estirpe criolla:
"A mi tío don 'Miguel
Cura hicieron de San Blas
Canónigo se hizo él.
Háganme a mí coronel
y yo me haré lo demás...."

\section{Retrato de Lima.}

Entre la varia y dispersa actividad de Fuentes existe, sin embargo, una nota de grave profundidad. Su cariño por Lima fué cabal y de una consciente y amplia ternura. Cariṇ̃o con conocimiento, como forma elevada dèl amor, Fuentes se sintió, en todo momento, entrañablemente unido al destino de la ciudad, y fué cronista predilecto de sus prestancias, lcomo lo podría haber sido Ricardo Palma o José Gálvez.

Cuando se trata de Lima su ironía deja de ser afilada hoja, para mostrar, en cambio, los destellos de su bruñido metal. Historiả yl anécdota se dan citasen las páginas de su Estadística Generalpde limąi en sue Guía Histórico-Descriptiva, o en su posterior y maestra "Lima” culminación y síntesis de las anteriores.

Este dulcificar la acritud de su acento cuando trata de la querida ciudad, le concede ejecutoria de beatitud en sus fastos. Lima lo reconoció así en su Cuarto Centenario, e hizo stu elogio por labios de José Jiménez Borja. Y Varela y Orbegoso, a quien cupo la suerte de prologar la reedición de la obra de Fuentes, subrayó el sentido de Lima y su cronista, en galanas frases:

"Tocó a Manuel Atanasio Fuentes-escribe Varela y Orbegoso-reunir en su libro brillante, la vida rumorosa de 
la ciudad en inquietud; sus templos, y sus ceremonias religiosas; sus saraos espléndidos y sus fiestas rutilantes; sus costumbres aristocráticas y sus hábitos populares; el noble de ilustre prosapia y el poeta festivo, atrevido y simpático; el clérigo de campanillas y la tapada misteriosa y bella; el abogado astuto y el mentecato popular y proverbial. Edificios, costumbres, tipos, viven en las páginas jugosas, ricas de Fuentes".

En la Estadística General de Lima, con justeza y elogio, puede afirmarse que Fuentes se traiciona a sí mismo. Con toda austeridad se propone forjar un libro rígido, lleno de apretadas cifras exactas, índice de la ciudad; pero la anécdota lo vence, se apodera de él e invade el libro con una simpatía y frescura incontenible. Llegan los colores, se transforman en pinceladas y surgen los cuadros donde palpita el espíritu de un pasado que no muere, sino se perenniza en nuevas formas.

La Estadística General de Lima responde a esta realidad. Los parajes, las iglesias y los edificios de la ciudad vibran en una cálida corporeidad. Sut presencia física se enrjquece con tenues tonăfiadescie qleyenda, queoles viene como de una familia antiquísima y gloriosa. Comprende Fuentes, que lo científico no es una negación de lo artístico, y la amenidad del derrotero preparado por sus manos, tiene ligeras genialidades de sabio, y constantes caprichos de poeta.

Guía para su presente y su futuro, pudo haber llamado Fuentes a su Guía de Lima. Libro breve y manuable pero apretado y enjundioso, sin ser árido. Goza hasta de la ingenuidad de sus litografías explicativas, y de los datos acuciosos que nos ilustran sobre peregrinos aspectos de la población. Sin su auxilio, hoy día, después de ochenta años, no podríamos reconstruir la fisonomía de la manera de $\underset{9}{\text { vivir de }}$ 
la ciudad predilecta. Hay una intensa preocupación, en estas páginas, de dar la noción del alma de sus gentes. Su transitar y su vivir está pintado con los más amplios caracteres. Sabemos de su genio, de sus vestidos, de sus comidas y sus fiestas, de sus devociones y sus defectos. Balance estadístico en lo numérico y también en ese condescendiente mundo de la simpatía a las cosas queridas.

A Fuentes le dolía que, fuera del Perú, pudiera existir una idea tan distinta de nuestra propia realidad. Por eso, encontrándose en París en I866, concibió la idea de escribir una obra, que traducida a varios idiomas permitiera al europeo tener una honrada idea ide nuestra patria. Así es como trazó los capítulos de su "Lima". Tenía un abundante material proveniente de las obras anteriores, pero su deseo era componer un libroágil y ameno que ganara una cabecera de puente-como diríamos ahora-en su avance sobre el espíritu de los extranjeros. Su empresa no fué frustrada, y su conquista, fué una conquista por comandos, ya que cada uno de los cuadros costumbristas que incluye en su obra, constituye una unidadpertrechada dectodas las armas de la simpatía

Sin desdeñar el datoeprecisave deecontenido numérico, grato a los paladares razonables, dedica toda una sección de su libro a una serie de pinturas de Lima y del Perú, bajo el título despreocupado de Brochazos y Pinceladas. En el brochazo está la nota de color local, en la pincelada el comentario caústico sobre tal o cual tipo, o tal o cual situación. Hace la exposición de las añejas costumbres de la ciudad engreída, trayendo a flor de labios la sonrisa risueña e incontenible. Sabemos, por ejemplo, que todo recién casado, tenía obligación de pasar un parte a sus amistades, concebido más o menos, en los siguientes términos: "Don N. N. participa a U. su enlace practicado con la señorita Doña N. N. y ambos se 
ofrecen a Ud en su nuevo estado"; manifestación a la que había que contestar con una visita donde se les deseaba felicidad "por muchos siglos y que Dios les concediese buena prole".

Los trajes y los manjares criollos; las felicitaciones y los dulces; las corridas de toros, las peleas de gallos y las noches buenas; Amancaes y Chorrillos; los carnavales y el miércoles de ceniza, todo queda aprehendido en esta retina de esquisita sensibilidad. Los médicos, como antaño lo hubiera hecho Juan del Valle Caviedes, son objeto, de una vengativa y concienzuda autopsia; y siguiendo esta línea de tipos, pinta al soldado y a la rabona, al aguador y al policía, al carretonero y a la lechera; al maestro de escuela y a todas las típicas celebridades de la ciudad. Pancho Fierro de nuestra literatura, por colorido y por alma, Manuel A. Fuentes, como Pardo, Segura y tantos otros, exigiría una estatua en alguna recatada alameda de la ciudad, donde por encima de las ternuras de los enamorados, extendiera él los pliegues de su capa y sus patillas al viento, como alas de Murciélago dispuesto a emprender el yuelo por todos los cielos del Perú.

\section{"Jorge Puccine Lurs Fabro Xammar.}

